\title{
Construction and Characterization of Organic Solar Cell and Study the Operational Properties
}

\author{
Majid H. Majeed* Mohamed Abdul Kareem** \\ Esraa H. Ali *** \\ * Middle Technical University/ Baghdad/Iraq \\ **,*** Department of Technical Material Engineering / Middle Technical University/ Baghdad/Iraq \\ *Email: mtuniversity@gmail.com \\ **Email: muhamedliver19@gmail.com \\ ***Email: esraa87hussein@gmail.com
}

(Received 10 July 2017; accepted 10 January 2018)

https://doi.org/10.22153/kej.2018.01.004

\begin{abstract}
This article reviews the construction of organic solar cell (OSC) and characterized their optical and electrical properties, where indium tin oxide (ITO) used as a transparent electrode, "Poly (3-hexylthiophene- 2,5-diyl) P3HT / Poly (9,9-dioctylfluorene-alt-benzothiadiazole) F8BT" as an active layer and "Poly(3,4-ethylenedioxythiophene)-poly (styrene sulfonate)" PEDOT: PSS which is referred to the hole transport layer. Spin coating technique was used to prepared polymers thin film layers under ambient atmosphere to make OSC. The prepared samples were characterized after annealing process at $\left(80^{\circ} \mathrm{C}\right)$ for $(30 \mathrm{~min})$ under non-isolated circumference. The results show a value of filling factor (FF) of (2.888), (0.233) and (0.28) and power conversion efficiency (PCE) of (0.0055), $\left(3.333 \times 10^{-6}\right)$ and $(0.0004)$, where these results were obtained by Keithley Electrometer Model 6517B, while spectral response is being utilized by LEOI-94 Monochromator and Keithley 6517B Electrometer.
\end{abstract}

Keyword: Organic Solar Cell, P3HT, F8BT, PEDOT, PSS, Spin Coating.

\section{Introduction}

The need for an energy where its sources are un-depleted, can be manufactured and environmentally friendly with no emitting of $\mathrm{CO} 2$. Sources do not need millions of years to produce naturally like oil and coal. All these requirements and needs make Organic solar cells the suitable solution where it also not causes soil toxicity if it was thrown away [1] and [2].

OSCs are a recommended technology nowadays due to their flexibility and low-cost production. Typically, the organic solar cell based on a blend of acceptor and donor material [3] and [4]. Depending on the acceptor material there are two types of OSCs; polymer/fullerene and polymer/polymer solar cell [5] Where the first group refers to a blend of polymer donor with fullerene derivative acceptor such as (P3HT: $\left.\mathrm{PC}_{61} \mathrm{BM}\right)$ which is intensively most studied and improved their efficiencies for about $10 \%$. The second group is indicating a blend of polymer donor with polymer acceptor which is investigated recently where their efficiencies are about $2 \%$ or less [5] and [6].

The organic solar cell OSCs is developed throughout the last ten years where this development including the synthesis of advanced material that been used, OSCs structure and fabrication process which is getting simple [4]. Depending on the displacement of charge carriers through the solar cell layers, the geometries of OSCs can be divided into two groups: the normal and the inverted solar cell [7] and [8].

The reason that makes fullerene derivative acceptor like PCBM give higher efficiencies than 
polymer acceptor like F8BT is due to the excitons dissociation, electron-hole mobility and the work function between Lowest Unoccupied Molecular Orbital (LUMO) donor and LUMO acceptor [5].

The working principle based on four stages [4] as shown in Fig.1. The following steps explain by details this mechanism:

1- Absorption of the incident light by the donor material through the transparent electrode (ITO) [3].

2- Generation of Excitons at the donor.

3- Excitons dissociation at the (D/A) interface, where the positive and negative charges transfer to the electrodes.

4- Charge collection at the electrodes.

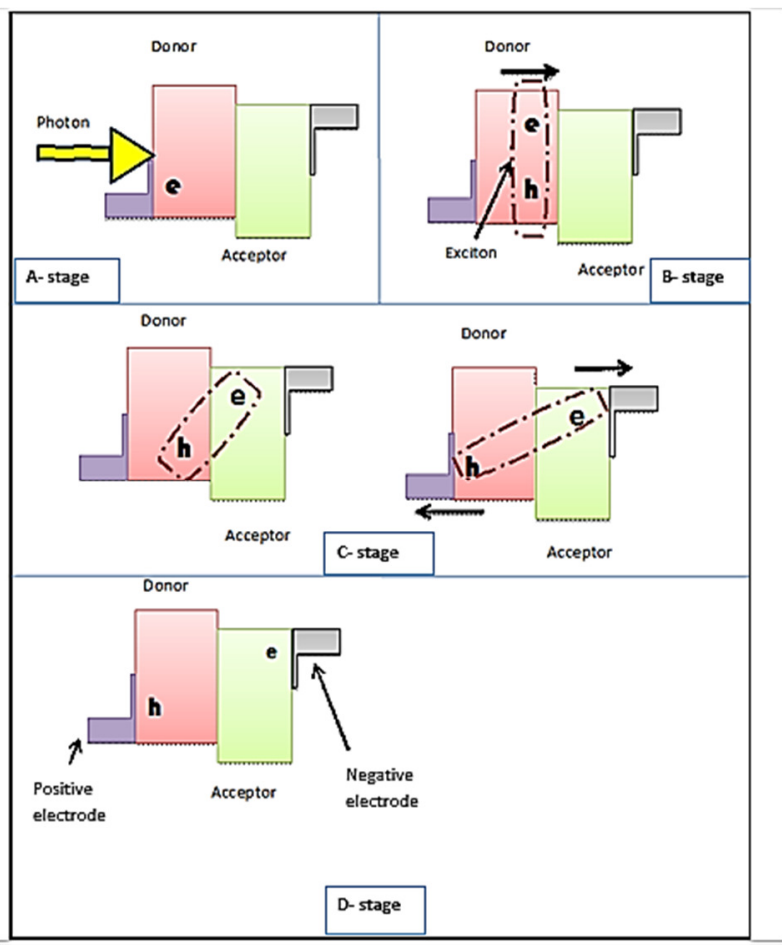

Fig. 1. The four stages of work principle that indicated by energy level.

The last stage refers to the collecting of charge carriers where electrons and holes move toward negative and positive electrodes, respectively [3], [4], [9] and [10]. The whole process of the normal organic solar cell can be summarized by the absorption of photons through the donor material where the electrons in "the Highest Occupied Molecular Orbital HOMO level" excited to "the Lowest Unoccupied Molecular Orbital LUMO level", which is no longer occupied LUMO level but instead of that there are "partially occupied molecular orbital POMO" [4]. The generated exciton is tending to shift toward the D-A interface. In the next stage, the electron in donor
LUMO level is transferred to the acceptor LUMO level [10]. It must be mentioned that the working principle of the inverted organic solar cell is a little bit different due to the layers' sequence.

\section{Solar Cell Parameters}

The power conversion efficiency PCE is the ratio of the output Power to the input power, where PCE [11].

$\mathrm{PCE}=\frac{F F J_{S C} V_{o C}}{P_{\text {in }}}$

The fill factor FF refers to the ratio of actual maximum power output $\left(P_{\max }\right)$ to the theoretical power output that represents the product of shortcircuit current and open-circuit voltage. [12]

$\mathrm{FF}=\frac{V_{m p} J_{m p}}{V_{o c} J_{s c}}$

The Spectral Response (S.R.) refers to the effect of the different incident light spectrum on a solar cell. If the produced current (I) in solar cell is divided by the incident light power $(\mathrm{P})$, the responsivity spectrum $\left(\mathrm{R}_{\lambda}\right)$ is produced with $(\mathrm{A} / \mathrm{W})$ unit [13] $\mathrm{R}_{\lambda}=\frac{I}{P}$

EQE or IPCE refers to "Incident Photon to Converted Electron" or "Internal Photon to Current Efficiency" which represents collecting photocurrent as a response to the incident light, as shows in the equation below [14]:

$I P C E=\frac{J_{s c(}\left(\mu A / \mathrm{cm}^{2}\right)}{P_{\text {in }}\left(\mu \mathrm{W} / \mathrm{cm}^{2}\right)} \times \frac{1240(\mathrm{eV} \mathrm{nm})}{\lambda(\mathrm{nm})}$

Where $P_{i n}$ is the input light irradiance $\left(\mathrm{W} / \mathrm{m}^{2}\right), \mathrm{V}_{\mathrm{mp}}$ and $\mathrm{J}_{\mathrm{mp}}$ are voltage and current at the maximum power, $\mathbf{J}_{\mathrm{sc}}$ is the short circuit current density $\left(\mathrm{mA} / \mathrm{cm}^{2}\right)$ or $\left(\mu \mathrm{A} / \mathrm{cm}^{2}\right), V_{o c}$; the open circuit voltage (volt) and $\lambda$ is the wavelength.

It is well known that every single device generating electricity has an internal series resistance. In the solar cell the internal resistance $\mathrm{R}_{\mathrm{s}}$ is a result of some reasons like the contact mode between the semiconductor and the electrode metal; the current flow direction through the emitter and solar cell as well as the resistance between two electrodes. [15] [16]

$\mathrm{I}_{\mathrm{sc}} \mathrm{R}_{\mathrm{s}}=\frac{n K T}{q} \ln \left(\frac{I_{O} q V_{o c} / n k T-I_{S C}}{I_{o}}\right)$

Where $\mathrm{Io}$ is the reverse saturation current $=$ $0.01 \mu \mathrm{A} / \mathrm{cm}^{2}, \mathrm{n}$ is the ideality factor $\approx 1, \mathrm{k}$ is the Boltzmann constant $=1.38^{*} 10^{-23} \mathrm{~J} / \mathrm{K}, \mathrm{T}$ is the temperature in Kelvin $(\mathrm{K}) \approx 300 \mathrm{~K}$ at room temperature and $\mathrm{q}$ is the charge of electron $=$ $1.6^{*} 10^{-19}$ C. [11] 


\section{Experimental Work 3.1 Sample Preparation}

ITO glass with $(3 * 3 \mathrm{~cm} 2)$ was etched from $(0.5 \mathrm{~cm})$ tip by HCL acid with zinc grain and cleaned by acetone for $10 \mathrm{~min}$ with magnetic stirrer then with $(0.2 \%)$ (Hellmanex III Ossila, C141) dissolved in DI-water for $10 \mathrm{~min}$ in magnetic stirrer after that the samples were immersed inside hot DI-water for 10 min with stirrer then the samples were stored in DI-water at ambient temperature.

On the top of cleaned ITO sample, a hole transport layer of "Poly (3,4-ethylene dioxythiophene)- poly (styrene sulfonate) PEDOT: PSS" (Ossila, M124) was spin coated at $(3000 \mathrm{rpm})$ for $(60 \mathrm{sec})$, annealed at $\left(150^{\circ} \mathrm{C}\right)$ for (10 min). The active layer was constructed from "Poly (3-hexylthiophene- 2,5-diyl) (P3HT)" (Ossila, M102) and "Poly (9,9-dioctylfluorene-alt benzothiadiazole) (F8BT)" (Ossila, M231) as "donor/acceptor bulk heterojunction (BHJ)", where it is prepared by dissolved in chlorobenzene and stirrer at $\left(70^{\circ} \mathrm{C}\right)$ over 14 hours in darkroom. This blend is spin coated at $(2000,3000 \& 2500$ $\mathrm{rpm})$, where these samples are annealed at $\left(80^{\circ} \mathrm{C}\right)$ for $(30 \mathrm{~min})$. An Aluminum electrode was evaporated by vacuum thermal evaporation at the etching tip. The design of sample is illustrated in Fig. 2.

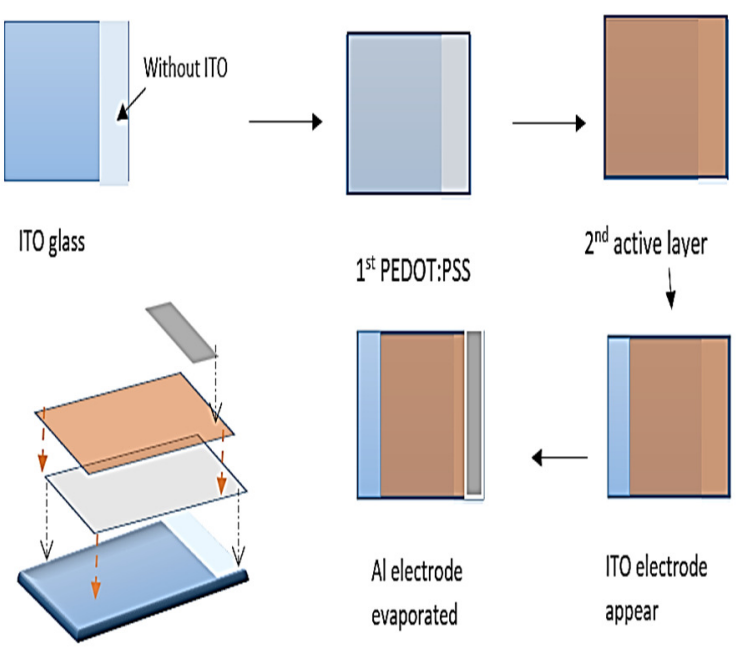

Fig. 2. Fabrication sequences of normal OSC device with BHJ blend ITO/PEDOT: PSS/P3HT:F8BT/Al.

\subsection{Device Characterization}

Keithley 6517B Electrometer with a tungsten lamp $(1200 \mathrm{~W} / \mathrm{m} 2)$ gives the JV- curve of each sample while the spectral response is being utilized by LEOI-94 Monochromator and Keithley 6517B Electrometer. Fig.3 and Fig.4 show these devices.

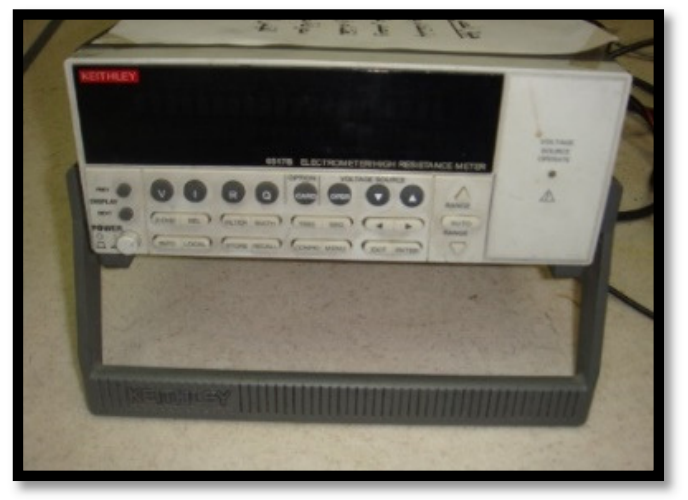

Fig. 3. Keithley 6517B Electrometer.

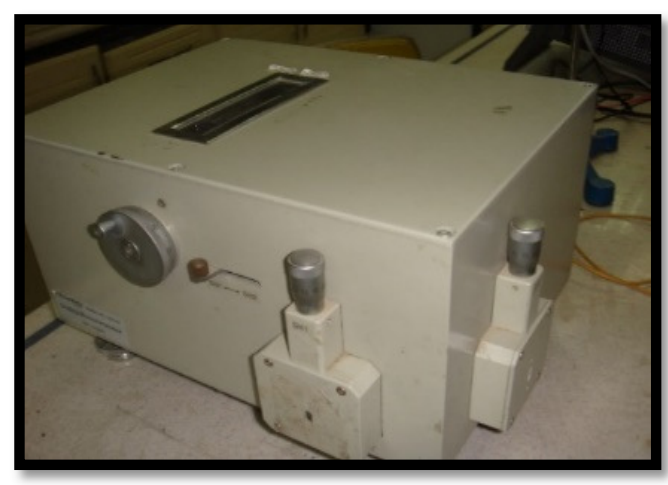

Fig. 4. LEOI-94 Monochromator.

\section{Results and Discussion}

The complete device is illustrated in Fig (5) exhibiting a homogeneous and uniform distribution for PEDOT: PSS and the blend due to using static dispense method which refers to add a suitable amount of solution for whole the substrate and then rotates it. The current density-voltage $(\mathrm{J}-\mathrm{V})$ curve for the three samples illustrated in Figures (6), (7) and (8). These figures show results that indicate a low Voc and Jsc which means low FF and PCE as illustrated in table (1), (2), (3), (4) and (5) where these low electrical properties are due to the non-isolated fabrication process where sample exposed to oxygen and humidity also the electrodes are connected to copper $(\mathrm{Cu})$ wire by indium (In) at each tip (electrodes) this increase the series resistance Rs. [15]

While the optical properties were affected by the spin coater speed that effects on the thickness of thin film. The spectral response shows the effect 
of different wavelength on output current for OSC. IPCE is more elementary than Responsivity which is used in theory. [17]

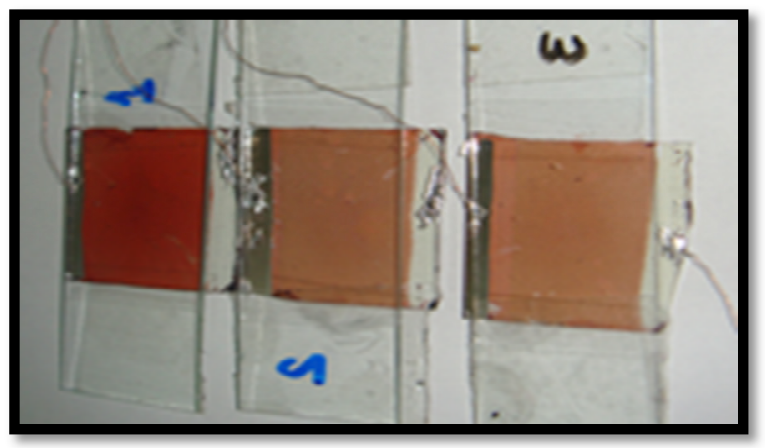

Fig. 5. Normal OSC picture of samples.

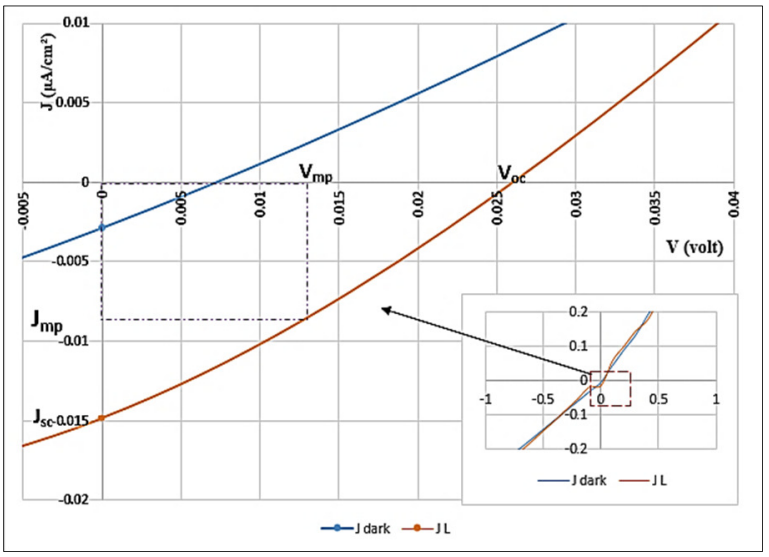

Fig. 6. JV curve of $(2000 \mathrm{rpm})$ spin coater speed sample.

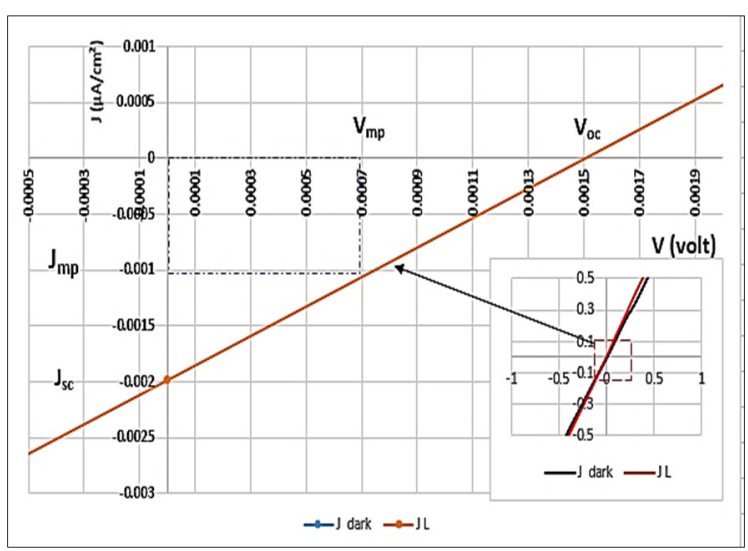

Fig. 7. JV curve of $(3000 \mathrm{rpm})$ spin coater speed sample.

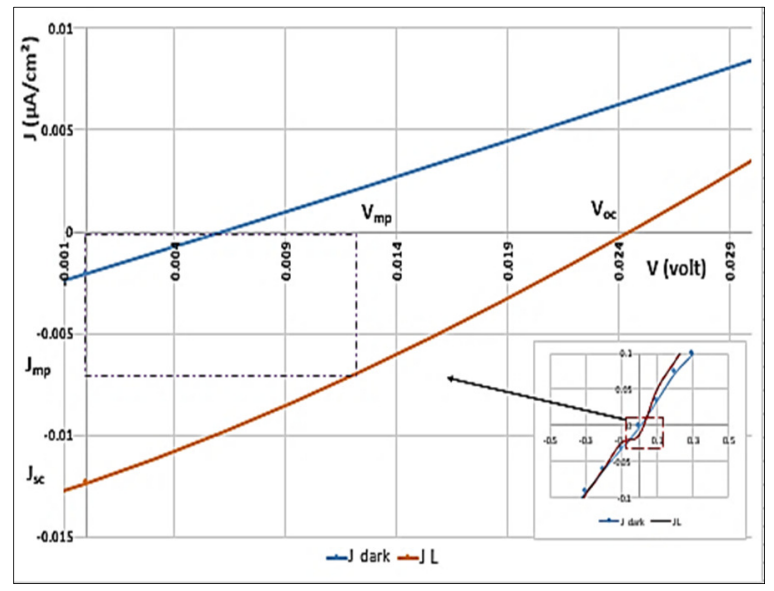

Fig. 8. JV curve of $(2500 \mathrm{rpm})$ spin coater speed sample.

\subsection{Calculations of Electrical Properties}

By Keithley Electrometer results for each sample we can calculate FF, PCE and Rs as shown in results table (1), (2), (3) and (4)., $P C E=$ $\frac{J_{m p} V_{m p}}{P_{\text {in }}}$ and

$\mathrm{I}_{\mathrm{sc}} \mathrm{R}_{\mathrm{s}}=\frac{n K T}{q} \ln \left(\frac{I_{o} q V_{o c} / n k T-I_{S C}}{I_{o}}\right)$

Where $\mathrm{I}_{\mathrm{sc}}=\mathrm{J}_{\mathrm{sc}} \times 9 \mathrm{~cm}^{2}$

For $\mathrm{P}_{\text {in }}=2100 \mathrm{~W} / \mathrm{m}^{2}=0.21 \mathrm{~W} / \mathrm{cm}^{2}$

Table 1,

Electrical results obtained by Keithly Electrometer

\begin{tabular}{lllll}
\hline Sample No. & Vmp & Jmp & Voc & Jsc \\
\hline Sample-1- & 0.013 & 0.09 & 0.027 & 0.015 \\
Sample-2- & 0.0007 & 0.001 & 0.0015 & 0.002 \\
Sample-3- & 0.012 & 0.007 & 0.024 & 0.0125 \\
\hline
\end{tabular}

Table 2,

Fill Factor results

\begin{tabular}{lll}
\hline FF & $\frac{\boldsymbol{V}_{\boldsymbol{m} \boldsymbol{p}} \boldsymbol{J}_{\boldsymbol{m} \boldsymbol{p}}}{\boldsymbol{V}_{\boldsymbol{o c}} \boldsymbol{J}_{\boldsymbol{s c}}}$ & Results \\
\hline $\mathrm{FF}_{1}$ & $\frac{0.013 \times 0.09}{0.027 \times 0.015}$ & 2.888 \\
$\mathrm{FF}_{2}$ & $\frac{0.0007 \times 0.001}{0.0015 \times 0.002}$ & 0.23333 \\
$\mathrm{FF}_{3}$ & $\frac{0.012 \times 0.007}{0.024 \times 0.0125}$ & 0.28 \\
\hline
\end{tabular}

Table 3,

Power conversion efficiency

\begin{tabular}{lll}
\hline PCE & $\frac{\boldsymbol{J}_{\boldsymbol{m} \boldsymbol{p}} \boldsymbol{V}_{\boldsymbol{m} \boldsymbol{p}}}{\boldsymbol{P}_{\boldsymbol{i n}}}$ & Results \\
\hline PCE $_{1}$ & $\frac{0.013 \times 0.09}{0.21}$ & 0.005571 \\
PCE $_{2}$ & $\frac{0.0062 \times 0.011}{0.21}$ & $3.333 \times 10^{-6}$ \\
PCE $_{3}$ & $\frac{0.012 \times 0.007}{0.21}$ & 0.0004 \\
& & \\
\hline
\end{tabular}


Table 4,

series resistance result

\begin{tabular}{|c|c|c|}
\hline $\mathbf{R}_{\mathrm{s}}$ & {$\left[\frac{n K T}{q} \ln \left(\frac{I_{o} q V_{o c} / n k T-I_{S c}}{I_{o}}\right)\right] \div I_{s c}$} & Result k $\Omega$ \\
\hline \multirow[t]{2}{*}{$\mathbf{R}_{\text {s1 }}$} & \multirow{2}{*}[0.02587\operatorname{ln}(\frac{(0.01\times1.6\times10^{-19}\times0.027/1\times300\times1.38\times10^{-23})-0.135\times10^{-6}}{0.01})]{$/ 0.135 \times 10^{-6}$} & \multirow[t]{2}{*}{199.97} \\
\hline & & \\
\hline \multirow[t]{2}{*}{$\mathbf{R}_{\mathbf{s} 2}$} & \multirow{2}{*}[0.02587\operatorname{ln}(\frac{(0.01\times1.6\times10^{-19}\times0.0015/1\times300\times1.38\times10^{-23})-0.018\times10^{-6}}{0.01})]{$/ 0.018 \times 10^{-6}$} & \multirow[t]{2}{*}{4092.705} \\
\hline & & \\
\hline $\mathbf{R}_{\mathrm{s} 3}$ & {$\left[0.02587 \ln \left(\frac{\left(0.01 \times 1.6 \times 10^{-19} \times 0.024 / 1 \times 300 \times 1.38 \times 10^{-23}\right)-0.1125 \times 10^{-6}}{0.01}\right)\right] / 0.1125 \times 10^{-6}$} & 17.256 \\
\hline
\end{tabular}

Table 5,

compering between Fill factor FF, power conversion efficiency PCE and series resistance Rs results

\begin{tabular}{|c|c|c|c|c|}
\hline Sample Number & Spin Coater Speed (rpm) & $\begin{array}{l}\text { Keithley Electrometer } \\
\text { FF }\end{array}$ & PCE & $\operatorname{Rs}(K \Omega)$ \\
\hline 1 & 2000 & 2.888 & 0.0055 & 200 \\
\hline 2 & 3000 & 0.233 & $3.333 \times 10^{-6}$ & 4093 \\
\hline 3 & 2500 & 0.28 & 0.0004 & 17.26 \\
\hline
\end{tabular}

The power conversion efficiency PCE and fill factor FF can be affected by the series resistance, where $R_{s}$ is due to the internal resistance of the OSCs at the electrode especially at the indium with copper wire and at the measurement device such as Keithley Electrometer.

\subsection{Calculations of Optical Properties}

While spectral response shows the effect of different wavelength on output current for organic solar cell OSC, the EQE illustrates the efficiency of OSC at different wavelengths. Quantum efficiency EQE is more elementary than Responsivity which is used in theory. Keithley Electrometer model 6517B with the grating monochromator give the optical properties of the organic solar cell.

$$
\begin{aligned}
& \mathrm{R}_{\lambda}=\frac{I}{P} \\
& \mathrm{IPCE}=\mathrm{EQE}=\frac{\mathrm{J}_{\mathrm{sc}(}\left(\mu \mathrm{A} / \mathrm{cm}^{2}\right)}{\mathrm{P}_{\mathrm{in}}\left(\mu \mathrm{W} / \mathrm{cm}^{2}\right)} \times \frac{1240(\mathrm{eV} \mathrm{nm})}{\lambda(\mathrm{nm})}
\end{aligned}
$$

For example, at wavelength of (500 nm).

$$
\begin{aligned}
& \mathrm{R}_{\lambda} 1=\frac{0.00025}{2.809}=8.899 \times 10^{-5} \mathrm{~mA} / \mathrm{W} \\
& I P C E=E Q E=\frac{0.02777\left({ }^{\mu A} / \mathrm{cm}^{2}\right)}{312111.11\left(\mu \mathrm{W} / \mathrm{cm}^{2}\right)} \times \frac{1240(\mathrm{eV} \mathrm{nm})}{500(\mathrm{~nm})} \\
& \mathrm{EQE}_{1}=2.2 \times 10^{-7} \\
& \mathrm{R}_{\lambda} 2=\frac{0.000775}{2.809}=2.758 \times 10^{-4} \mathrm{~mA} / \mathrm{W} \\
& I P C E=E Q E=\frac{0.08611\left({ }^{\mu A} / \mathrm{cm}^{2}\right)}{312111.11\left(\mu \mathrm{W} / \mathrm{cm}^{2}\right)} \times \frac{1240(\mathrm{eV} \mathrm{nm})}{500(\mathrm{~nm})} \\
& \mathrm{EQE}_{2}=6.8422 \times 10^{-7} \\
& \mathrm{R}_{\lambda} 3=\frac{0.000238}{2.809}=8.472 \times 10^{-5} \mathrm{~mA} / \mathrm{W} \\
& I P C E=E Q E=\frac{0.08611\left({ }^{\mu A} / \mathrm{cm}^{2}\right)}{312111.11\left({ }^{\mu W} / \mathrm{cm}^{2}\right)} \times \frac{1240(\mathrm{eV} \mathrm{nm})}{500(\mathrm{~nm})} \\
& \mathrm{EQE}_{3}=2.1 \times 10^{-7}
\end{aligned}
$$

Figure (9) indicates the effect of different spectrums on $(2000 \mathrm{rpm})$ spin coated sample OSC. In which the cell shows increased response from $(400 \mathrm{~nm})$ until reaching $(500 \mathrm{~nm})$, then a slight and gradual decrease in responsivity at $(600 \mathrm{~nm})$ followed by a slight increase at $(700 \mathrm{~nm})$ then a sharp decreased. This plot shows the proper band width is about (500-700 nm).

Figure (10) shows that at $(500 \mathrm{~nm})$, the maximum EQE was (0.000022\%), while this diagram gives information about the collected electron per incident light flux, it also shows a slight decrease in quantum efficiency. This decrease means that the incident light effect or $\left(\mathrm{P}_{\text {in }}\right.$ effect) is very small on the quantum efficiency of this cell.

Figure (11) indicates the effect of incident light on $(3000 \mathrm{rpm})$ spin coated sample where the highest responses at $(500 \mathrm{~nm})$ followed by a slight decrease then a little increase at $(750 \mathrm{~nm})$, where the bandwidth is about (500-750 $\mathrm{nm})$.

Figure (12) shows that at $(500 \mathrm{~nm})$, the maximum EQE was $(0.000068 \%)$. This IPCE was larger than that of sample-1-, this can explain by the effect of the fabrication process of this sample, where the spin coater speed was $(3000 \mathrm{rpm})$ this can decrease the thickness of active layer which effect on the efficiency of (electron/hole) pair generated and efficiency of interfacial charge transfer which effected on IPCE.

Figure (13) illustrated the spectral response of (2500 rpm) spin coated sample that shows a sensible response from $(500-750 \mathrm{~nm})$, where the highest response at $(500 \mathrm{~nm})$ followed by a slight decrease at $(650 \mathrm{~nm})$ then a little rise at $(750 \mathrm{~nm})$. Figure (14) shows that at $(500 \mathrm{~nm})$, the maximum EQE was $(0.000021 \%)$, where the spin coater 
speed was $(2500 \mathrm{rpm})$ this can decrease the thickness of active layer which increases the Quantum efficiency but the recombination of the charge carrier at the interface after examined for a while cause drop in IPCE.

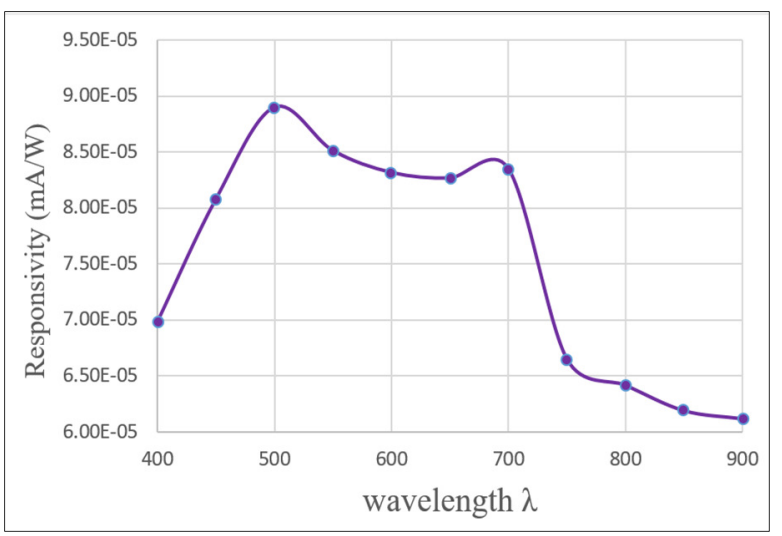

Fig. 9. Spectral Response of ( $2000 \mathrm{rpm})$ spin coated sample.

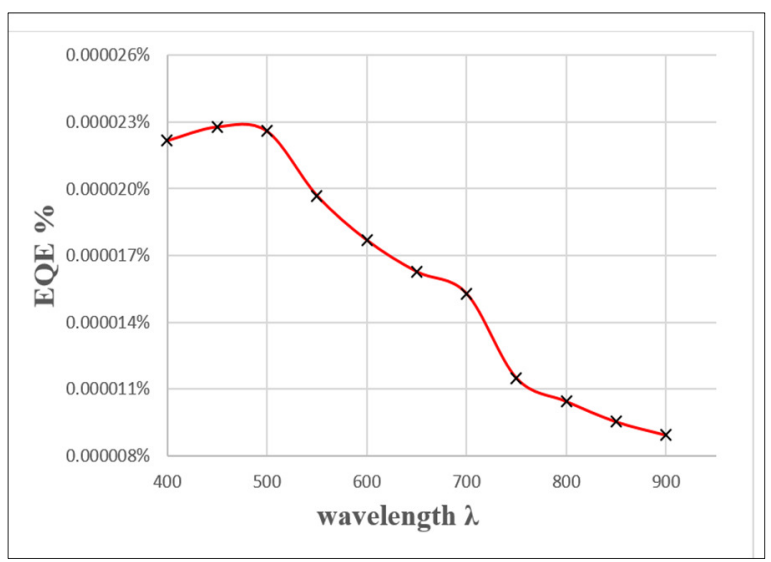

Fig. 10. Quantum Efficiency of (2000 rpm) spin coated sample.

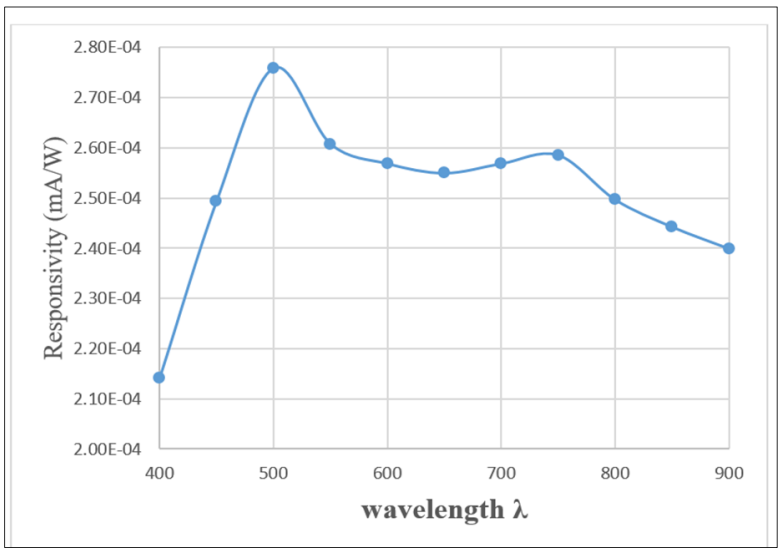

Fig.11. Spectral Response of $(3000 \mathrm{rpm})$ spin coated sample.

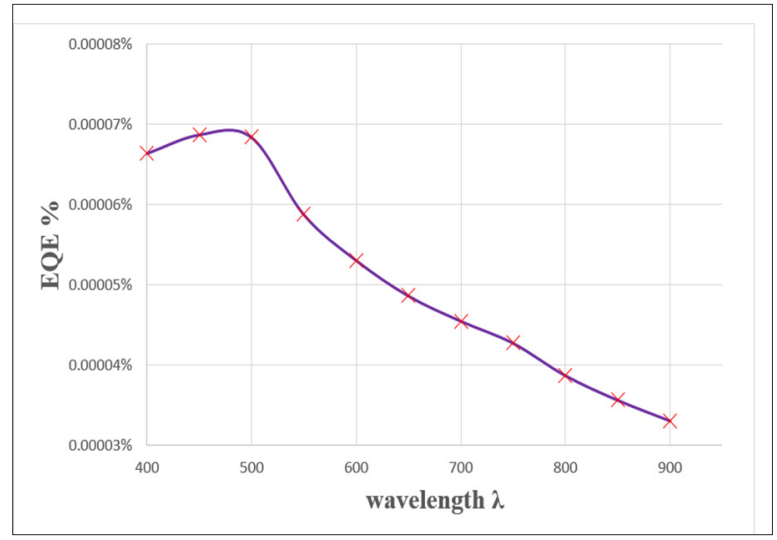

Fig. 12. Quantum Efficiency of (3000 rpm) spin coated sample

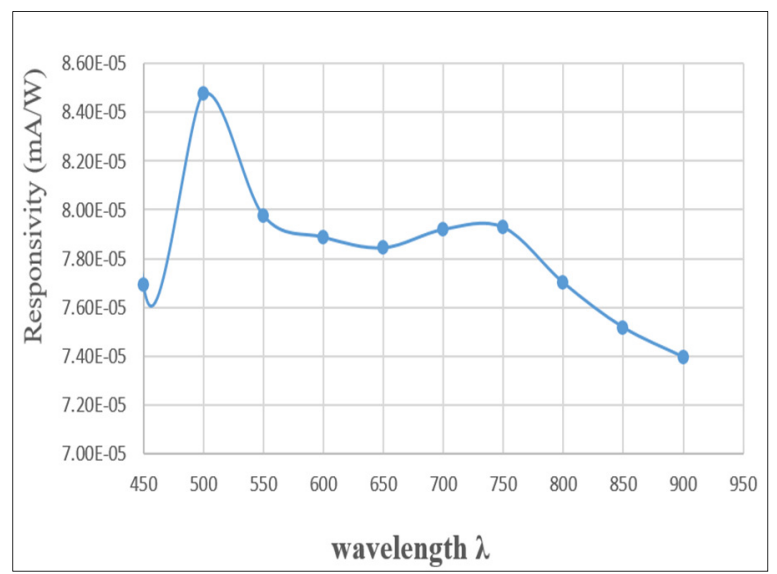

Fig.13. Spectral Response of $(2500 \mathrm{rpm})$ spin coated sample

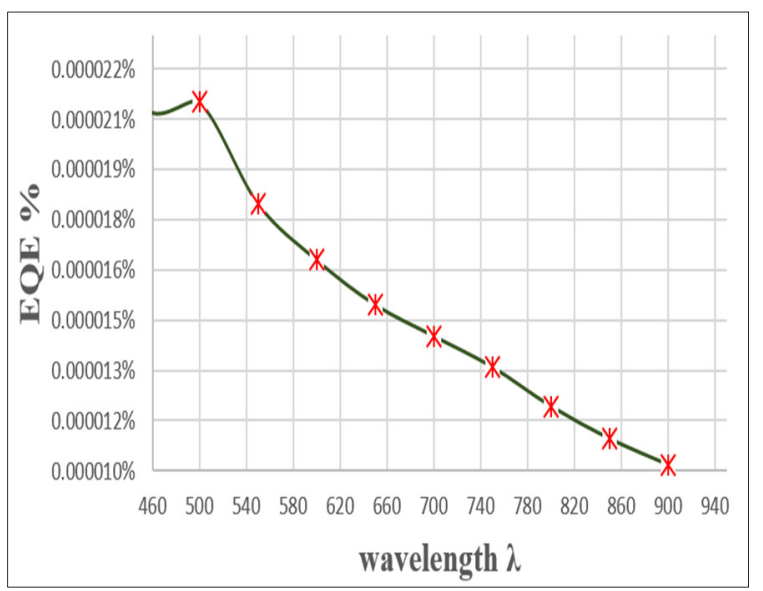

Fig. 14. Quantum Efficiency of (2500 rpm) spin coated sample 


\section{Conclusions}

The (2000 rpm) spin coated sample show stable electrical and optical properties while this sample is fabricated at (2000 rpm) which can be represented as the suitable speed for fabrication this type of organic solar cell. The power conversion efficiency PCE and fill factor FF can be affected by the series resistance, where $\mathrm{R}_{\mathrm{s}}$ is due to the internal resistance of the OSCs at the electrode especially at the indium with Copper

$(\mathrm{Cu})$ wire. The optical properties such as responsivity $\mathrm{R}_{\lambda}$ and IPCE is affected by the fabrication process by manipulating the thickness of active layer where it decreases with increasing speed of spin coater that effect on the donor/acceptor interface which effect on the exciton generation and collection. The results show the poor electrical properties of P3HT: F8BT blend due to the low work function where the P3HT LUMO/ F8BT LUMO offset is $(\sim 0.3 \mathrm{eV})$ and the suitable value generally is $(0.5$ $\mathrm{eV})$. Higher optical and electrical response can be obtained by reducing the annealing temperature up to $\left(80^{\circ} \mathrm{C}\right)$ for a longer time $(30 \mathrm{~min})$, this is due to the fabrication process is done at ambient condition without gloves-box. Using a static dispensation method can increase the homogeneity of spin-coated polymer layers and make a uniform thin film. The prepared samples from PEDOT: PSS dispersion is suitable to use dispersion without filtering or stirrer.

\section{Acknowledgement}

I would like to express my sincere gratitude and appreciation to my advisor Prof. Dr. Majid H. Majeed for his advice throughout the period of this research. True deep thanks and appreciation to Dr. Mohamed Abdul Kareem (رحمد الله) for his patience, motivation, enthusiasm, and knowledge. His guidance helped me in all the time of research and writing of this thesis. I could not have imagined having a better advisor and mentor for my thesis. I would like to thank all the people who have given help and I have not mentioned them.

\section{References}

[1] Horigome, T., Kimura, K., Takakura, T., Nishino, T., \& Fujii, I.; "Clean and Safe Energy Forever", I ed., Vol. 1, International Solar Energy Society Proceedings Series, Newnes, 2012, p 20.
[2]Zang, L.; "Energy Efficiency and Renewable Energy Through Nanotechnology", Green Energy and Technology. London: Springer Science \& Business Media. 2011, p 171.

[3] Kim, M. S.; "Understanding Organic Photovoltaic Cells: Electrode, Nanostructure, Reliability, and Performance", Dissertation on the degree "Doctor of Material Science and Engineering", University of Michigan, (2009), pp8-25.

[4]Renee Kroon, Martijn Lenes, Jan C. Hummelen, Paul W. M. Blom, And Bert De Boer; "Small Bandgap Polymers for Organic Solar Cells (Polymer Material Development in the Last 5 Years)", University of Groningen, Groningen, the Netherlands, Taylor \& Francis Group, 2008, pp 531- 540.

[5] Łukasz Bernacki, Zbigniew Lisik, Beata Łuszczyńska, "The evaluation of organic solar cell's properties based on polymer F8BT and fullerene derivative C60PCBM", Przegląd Elektrotechniczny, R. 91 NR 9, 2015, p 13.

[6]Seth Marder \& Kwang-Sup Lee, Photoresponsive Polymers II, vol. 2014, Advances in Polymer Scienc, Springer, 2008, pp. 4-5.

[7] Wallace C.H. Choy; "Organic Solar Cells: Materials and Device Physics, Department of Electrical and Electronic Engineering", University of Hong Kong, China, Green Energy and Technology, Springer Science \& Business Media, 2012, pp 160-161.

[8] Barry P. Rand, Henning Richter; "Organic Solar Cells: Fundamentals, Devices, and Upscaling", Taylor \& Francis group, CRC Press, 2014, chapter -15, pp (713-725-727-730221).

[9]Rieger, R.; "Extended Donor and Acceptor Molecules for Organic Electronics", Dissertation on the degree "Doctor of Science", The Department of Chemistry, pharmacy and Geosciences Johannes Gutenberg - university Mainz, 2009, p 11.

[10] Barry C. Thompson, Jean M. J. Fréchet; "Polymer-Fullerene Composite Solar Cells", Volume 47, Issue 1, Angewandte Chemie International Edition, 2007, p 60.

[11] Qing Zhang, W. I. Milne; "Advances in Nanodevices and Nanofabrication: Selected Publications from Symposium of Nanodevices and Nanofabrication in ICMAT2011", Taylor \& Francis group, CRC Press, 2012, p 103.

[12] Jha, A. R.; "Solar Cell Technology and Applications", CRC Press, 2009 p 94. 
[13] Stuart R. Wenham, Martin A. Green, Muriel E. Watt, Richard Corkish, Alistair Sproul; "Applied Photovoltaics", 3rd ed, Routledge, 2011, p 45.

[14] Bo Wu, Nripan Mathews, Tze-Chien Sum; "Plasmonic Organic Solar Cells: Charge Generation and Recombination", SpringerBriefs in Applied Sciences and Technology, Nanoscience and Nanotechnology, Springer, 2016, pp (7-3940).

[15] K.L. Chopra, S.R. Das ; “Thin Film Solar Cells", 1st ed., Springer Science \& Business Media, 1983, pp 130-131.
[16] Ramchandra Pode, Boucar Diout; "Solar Lighting", Springer Science \& Business Media, 2011, p 32.

[17] Ronald G. Driggers; "Encyclopedia of Optical Engineering: Pho-Z, Marcel Dekker", Dekker Encyclopedias Series, vol.3, Encyclopedia of Optical Engineering, CRC Press, 2003, p 2200. 


\title{
بناء وتوصيف الخلايا العضوية ودراسة خصائص التشغيل
}

\author{
إسراء حسين علي***

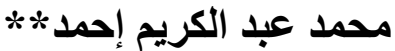 \\ ماجد حميد مجيد

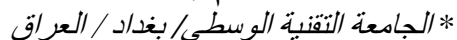

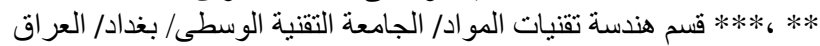

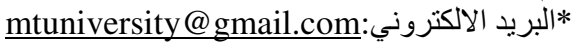

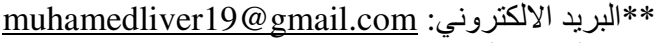 \\ esraa87hussein@gmail.com:البريد الالكتروني:**** الإني
}

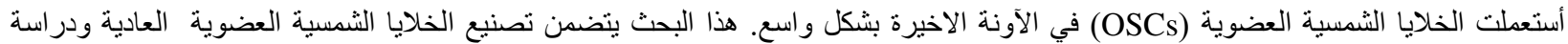

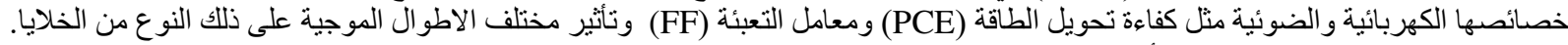

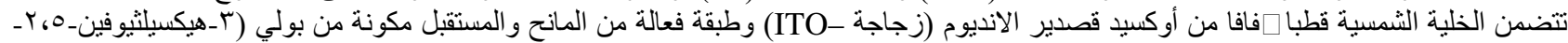

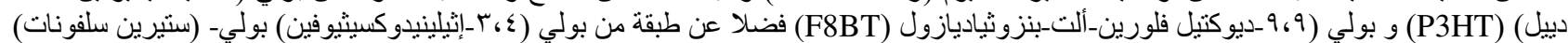
(PEDOT: PSS )

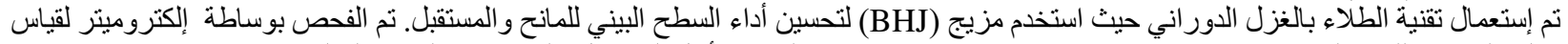

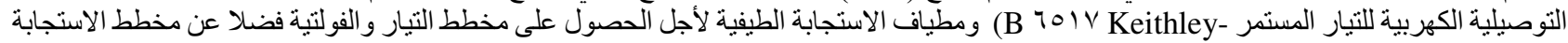

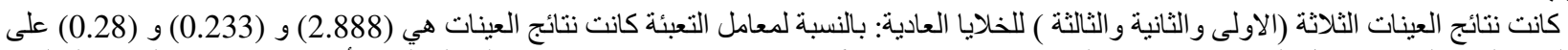

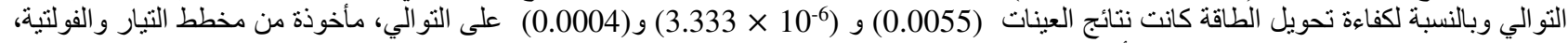

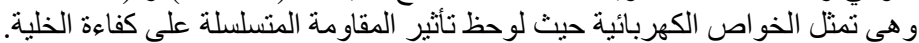

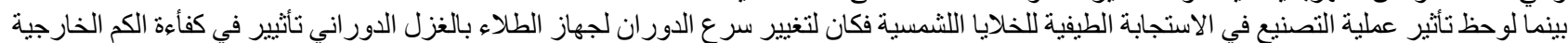

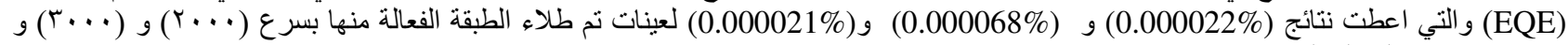
على التو الي. rpm (Yo...) 